\title{
APÊNDICE:
}

As atividades de ensino 
Apêndice A

Apresentação: Auto-retratos

\section{Marc Chagall}

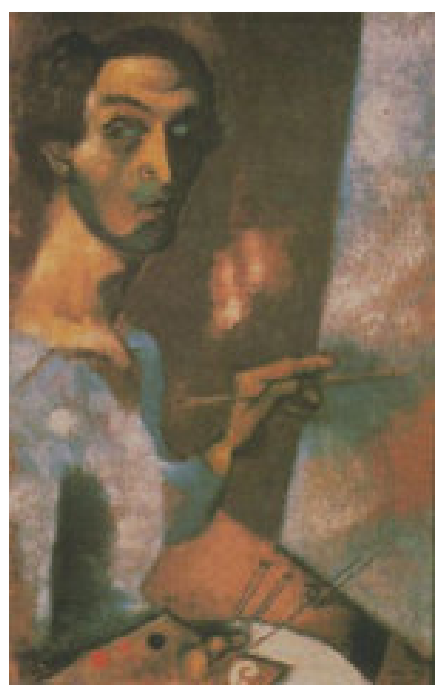

Auto-retrato

1914

\section{Paul Cèzanne}

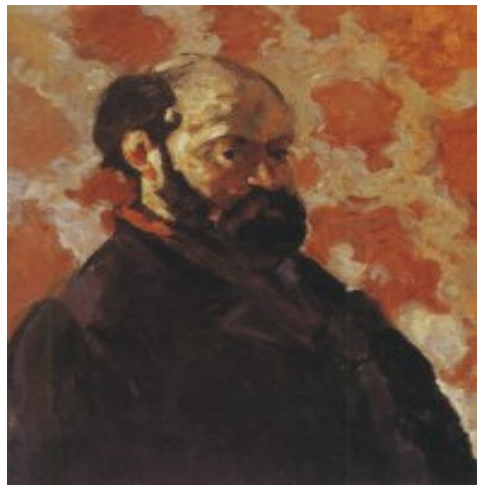

Retrato do artista

$1875 / 1877$ 


\section{Henri Matisse}

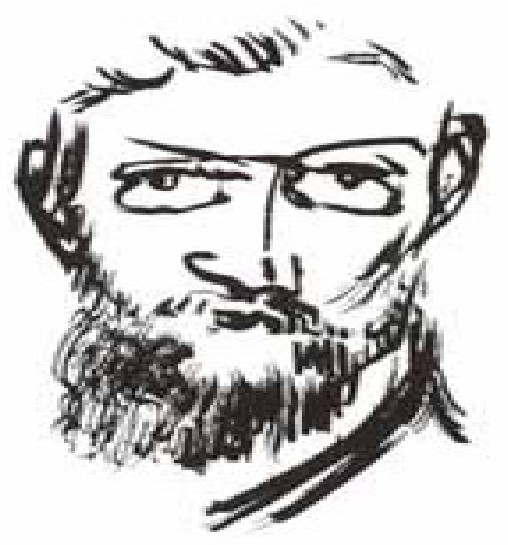

Auto-retrato

1900

\section{Peter Paul Rubens}

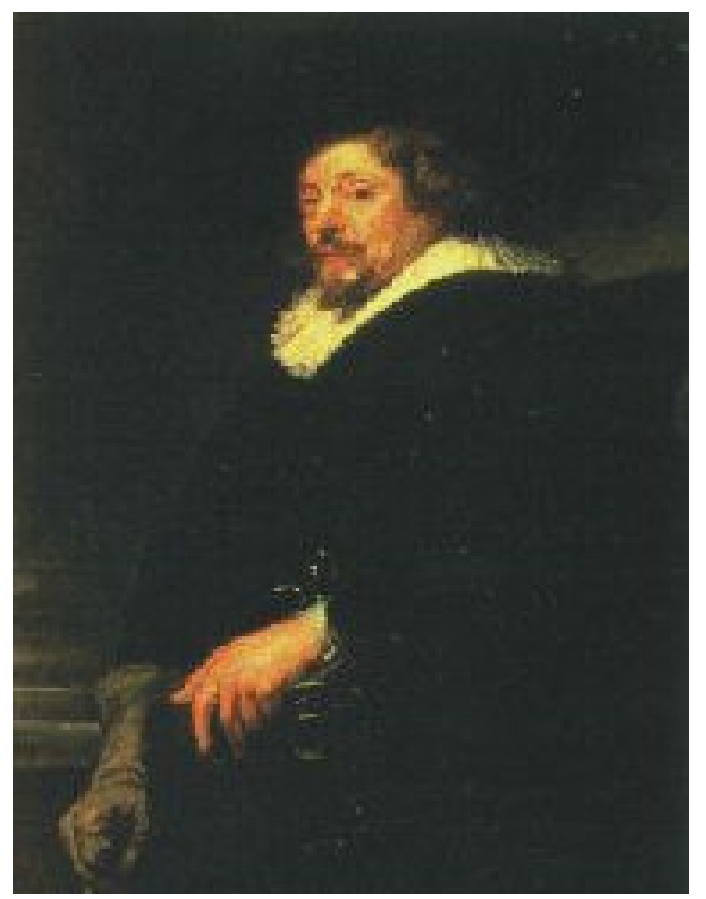

Auto-retrato

c. 1639 


\section{Rembrandt Van Rijn}

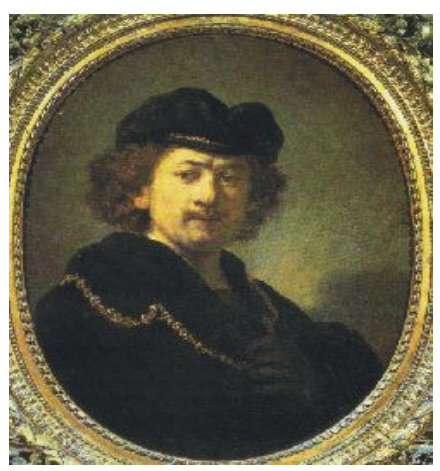

Auto-retrato

1663

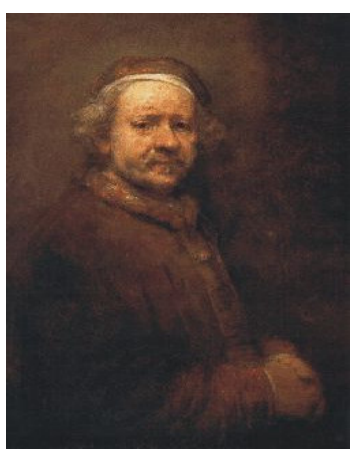

Auto-retrato

1669

\section{Pierre August Renoir}

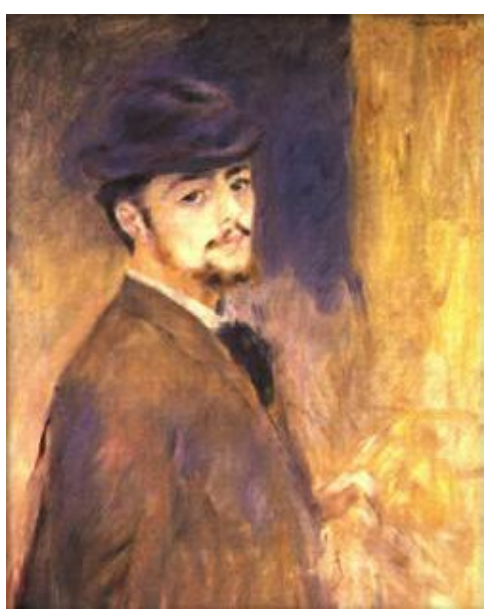

Auto-retrato

1876 


\section{Vincent Van Gogh}

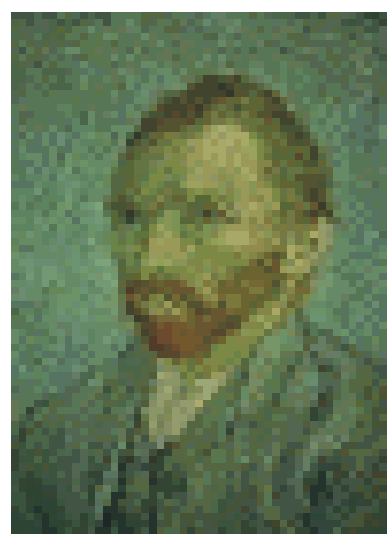

Auto-retrato

1889

Joan Miró

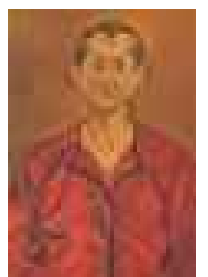

Auto-retrato

1919 


\section{Apêndice B \\ Mancala adaptado}

\section{Regras}

\section{Objetivo do Mancala Adaptado:}

Ser o jogador com o maior número de fichas.

Número de jogadores: 2

\section{Peças:}

13 fichas com valor 1 e uma ficha especial para cada jogador.

\section{A ficha especial:}

Temos dois tipos de fichas especiais. Uma ficha que tem valor 2 e outra que diminui em dois pontos o valor da ficha do adversário na casinha em que esta estiver posta. Cada jogador tem somente um tipo de ficha especial, ou seja, ou tem a que tem valor 2 ou a que diminui 2 pontos do adversário.

\section{Preparando o jogo:}

Faz-se um sorteio para que cada jogador escolha uma cor e um lado do tabuleiro para ser seu.

\section{Jogando:}

Cada jogador na sua vez tem que distribuir suas fichas nas casinhas, iniciando pelas casas do adversário. Em cada casinha devem ser postas no mínimo uma ficha, esta limitação deve ser seguida somente na primeira rodada de cada um dos jogadores. Após o primeiro jogador distribuir suas fichas, não é necessário à distribuição de todas, ele passa a sua vez para o outro jogador e que faz o mesmo procedimento. Após os dois jogadores distribuírem as fichas com valor unitário, eles podem usar as fichas especiais mas somente no seu campo de jogo.

\section{Capturando as fichas:}

Após a distribuição das fichas, começamos a fase de captura de fichas. A captura das fichas é feita da seguinte maneira. Em cada casinha faz a soma dos valores das fichas, observando se na casa está ou não com uma ficha especial. Leva a ficha da casinha aquele jogador que tiver maior valor de pontos na casinha, se houver empate, nenhum dos jogadores captura as fichas.

Após a captura das fichas o jogador troca àquelas fichas capturadas do adversário por outras suas e as inclui na próxima distribuição.

\section{Vencedor do jogo:}


É considerado vencedor do jogo aquele que capturar todas as fichas do adversário ou quando o adversário não tiver fichas suficientes para distribuir na primeira rodada uma ficha em cada casa.

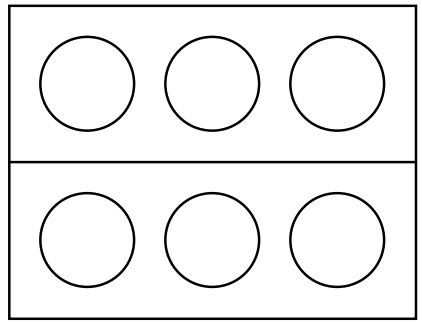

O tabuleiro

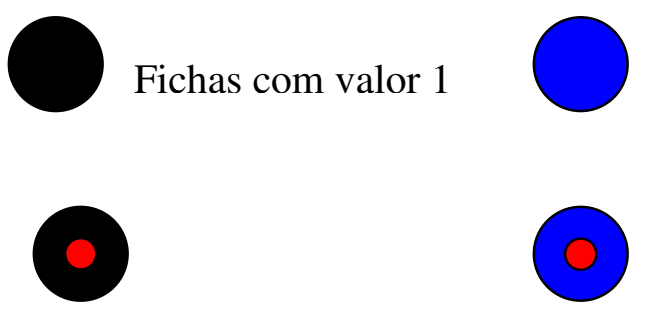

Ficha especial valor 2 


\section{Uma simulação de uma partida}

A primeira rodada, distribuição das fichas azuis.

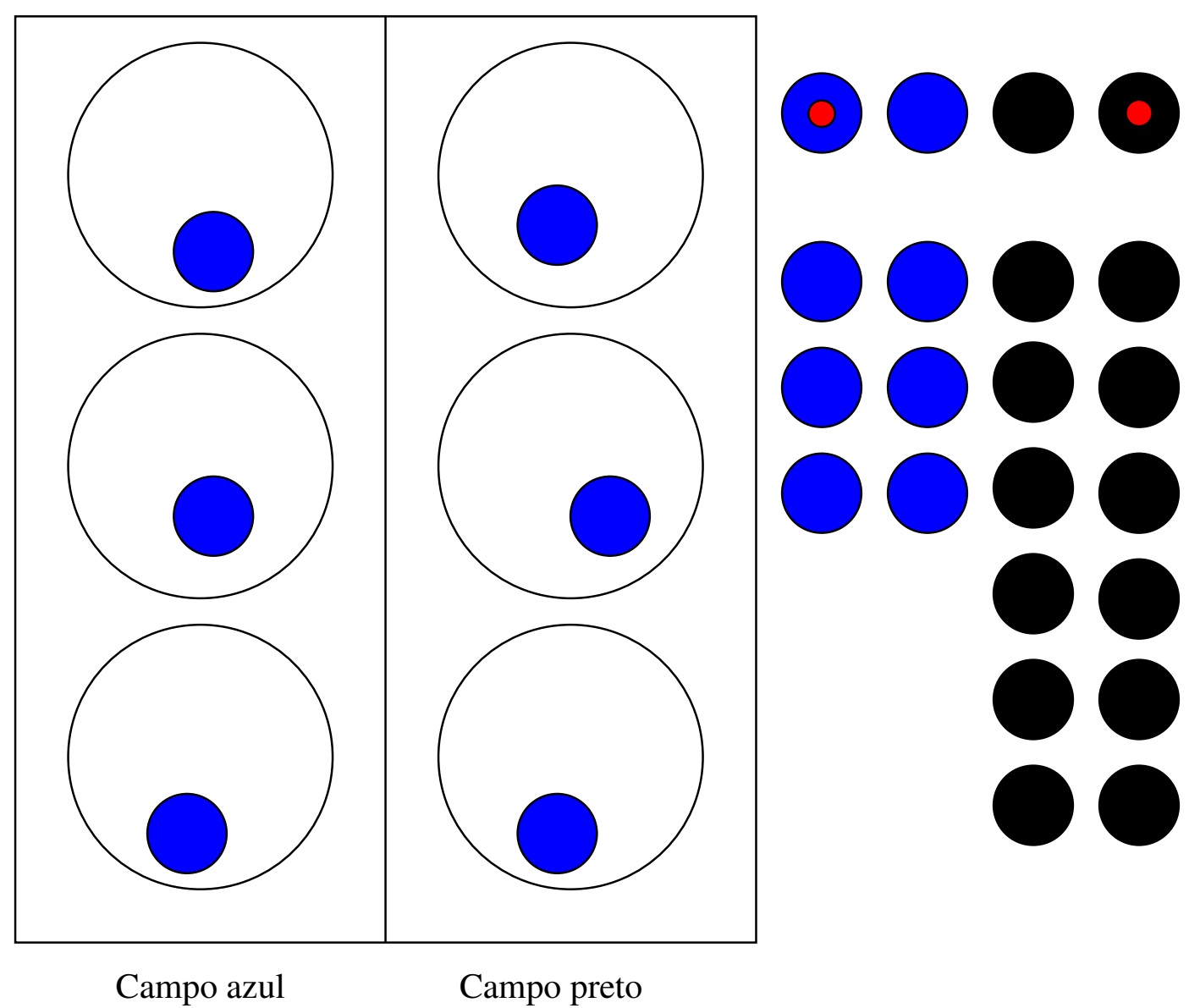


Segunda rodada, a distribuição das fichas pretas.
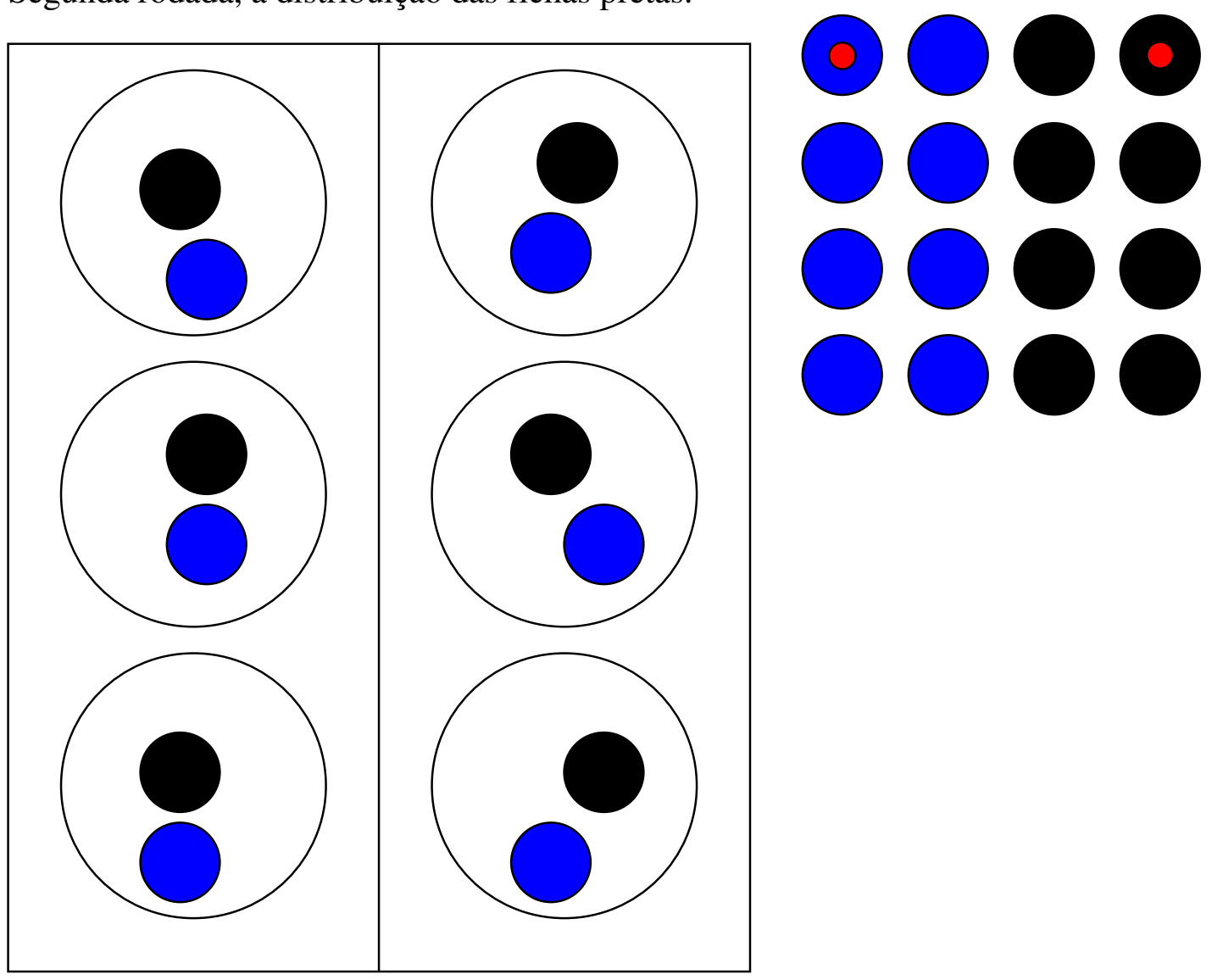

Campo azul

Campo preto 
Terceira rodada, nova distribuição das fichas azuis.
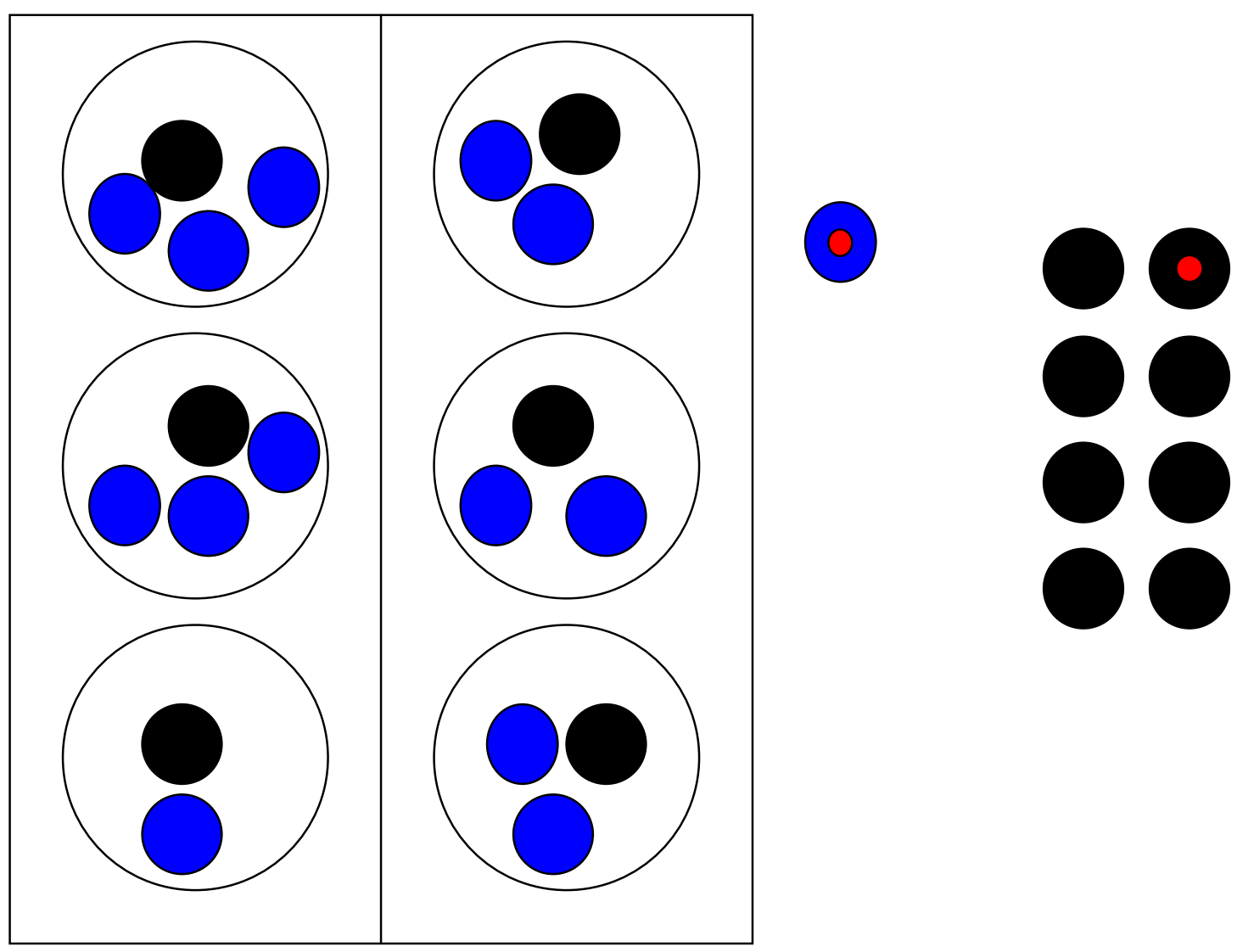

Campo azul

Campo preto 
Quarta rodada, nova distribuição das fichas pretas.

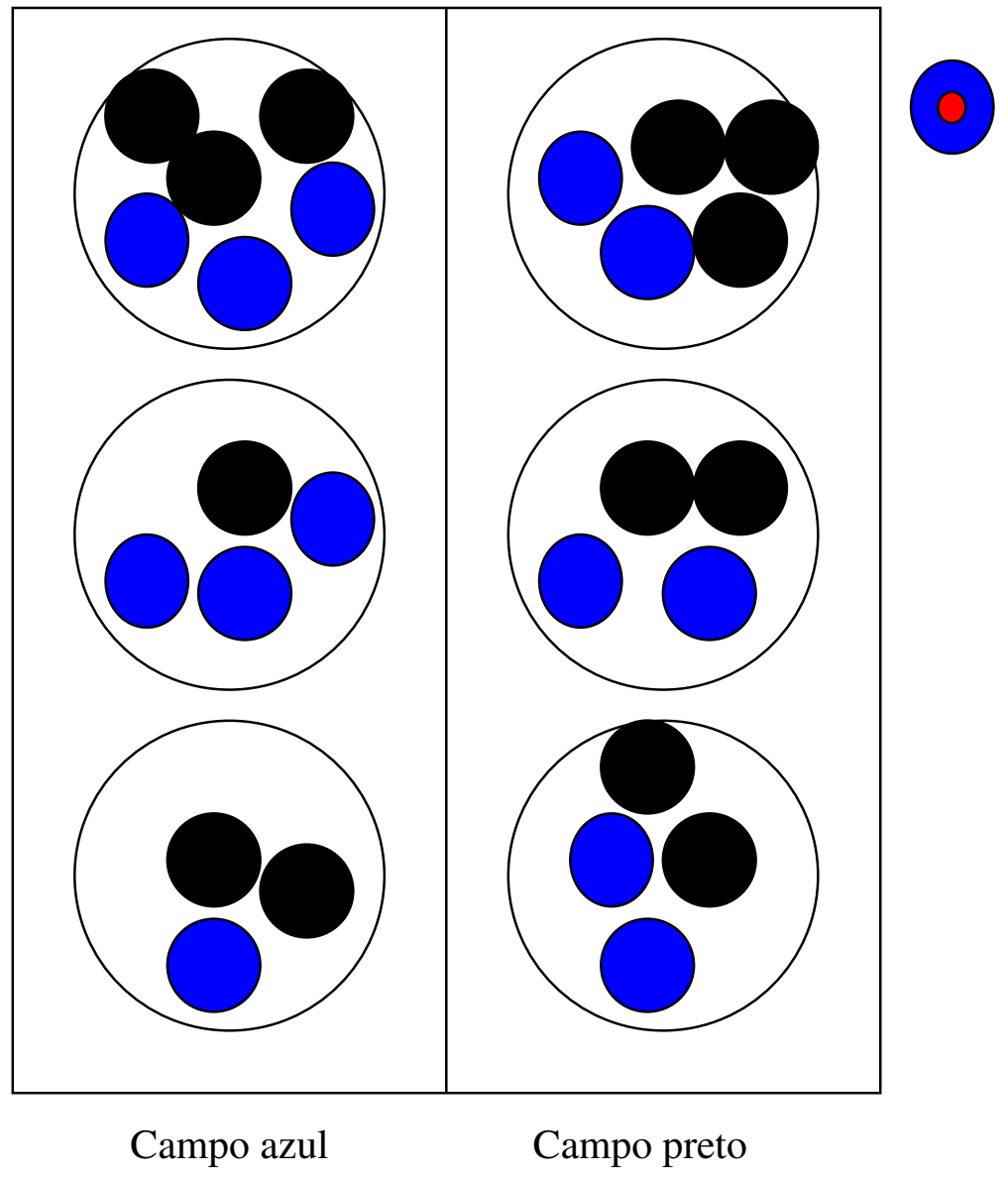


Quinta rodada, o uso das fichas especiais.

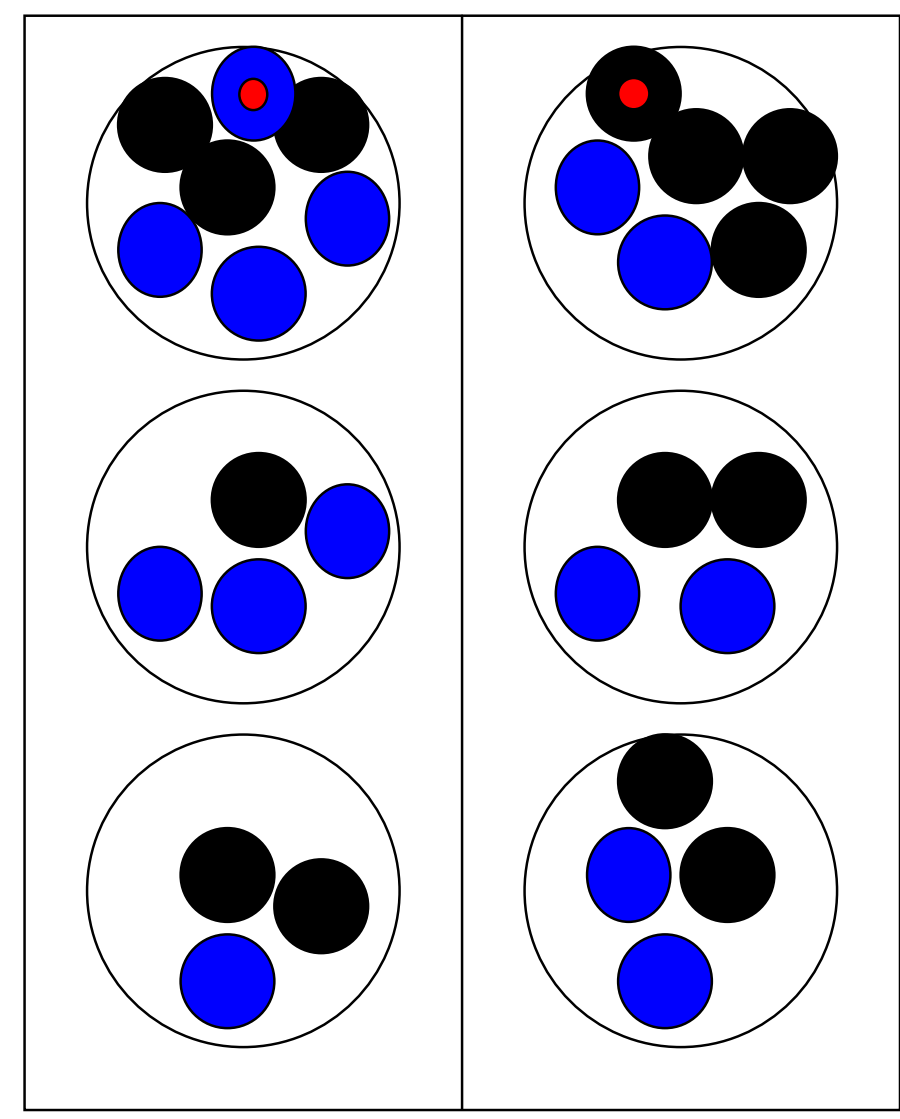

Campo azul

Campo preto 
A captura das fichas.

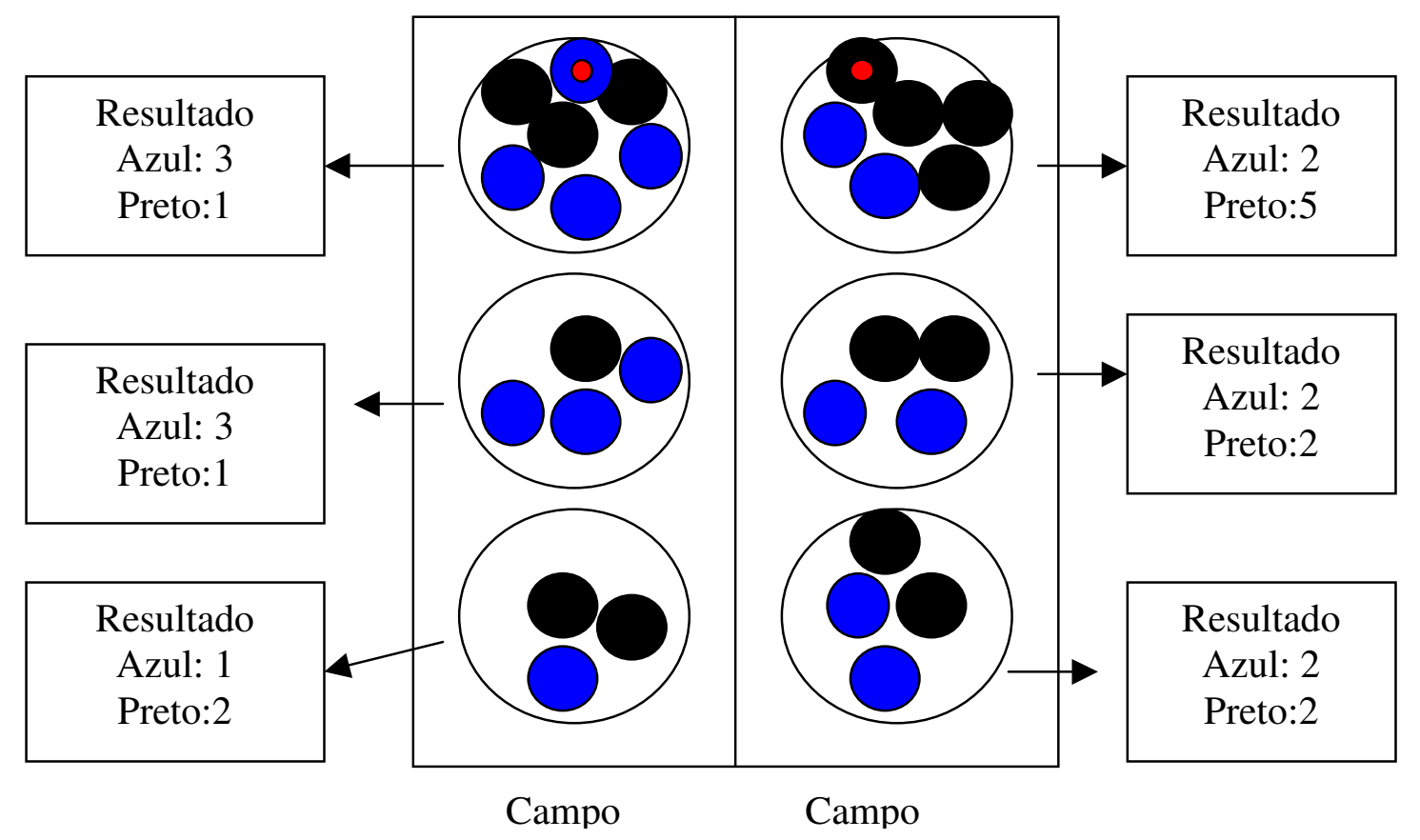

Resultado da captura:

\begin{tabular}{|c|c|}
\hline Cor & Fichas capturadas \\
\hline Azul & 4 \\
\hline Preto & 3 \\
\hline
\end{tabular}

Após isto o jogo prossegue só que agora o jogador azul terá 14 fichas (ele deve trocar a ficha preta capturada por uma da sua cor) e o jogador preto terá 12. 


\title{
Apêndice C \\ Robozinho
}

\section{Comandos do robô}

\section{Palavras que o Robô compreende:}

\author{
ANDAR \\ VIRAR \\ DIREITA \\ ESQUERDA \\ ORGANIZAR EM LINHAS \\ TIRAR \\ ACRESCENTAR \\ DISTRIBUIR \\ CARREGAR \\ CONTAR \\ GRAVAR \\ UM \\ DOIS \\ Quantidades
}

Andar; quantidade

Virar; direção

Tirar, quantidade

Retirar, quantidade

Distribuir, quantidade

Carregar, quantidade

Acrescentar; quantidade

Organizar em linhas; contar; gravar

\section{OBJETIVOS DO GRUPO}

1. Sair de A1 e chegar em D5 sem fazer uso do mesmo comando repetidamente.

2. Sair de A1 e chegar a $\mathrm{C} 4$ e retornar a A1 sem passar pelo mesmo caminho.

3. Sair de A1 distribuir igualmente todas as peças do saquinho em três casinhas vazias, organizar e contar os objetos na casa D2, recolher os objetos em B2 e depositar em A3, sair em D5 com dois objetos grandes.

4. Crie um movimento usando todos os comandos que o robô compreende. 


\section{Apêndice D \\ O diário do Sr. Tobias}

O sr. Tobias é uma pessoa como você. Ele tem sua família, trabalha, paga os seus impostos, diverte-se, etc. Porém, o sr. Tobias, tem um hábito muito interessante. Como ele é uma pessoa bastante metódica, ou seja, sempre faz as coisas com uma total ordenação, ele possui um diário, em outras palavras um livro onde escreve todo os movimentos que ocorrem na sua vida, principalmente aqueles relacionados às questões financeiras. Veja umas das páginas do diário do sr. Tobias:

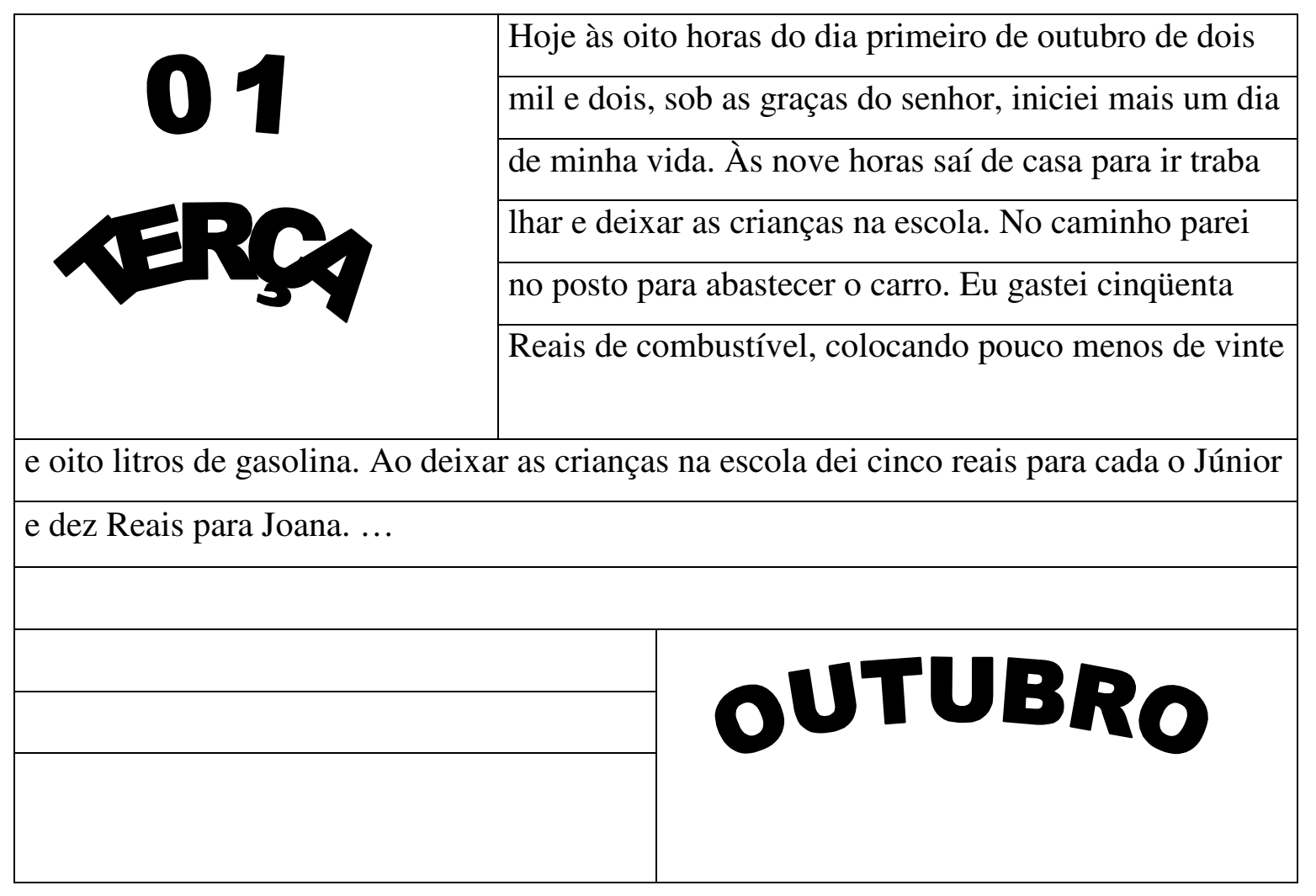

E por ai foi o registro do sr. Tobias.

A proposta de atividade é a seguinte, nós vamos trabalhar com o jogo "Dinheiro do mês" e vamos simular os gastos durante um período de tempo, no caso dois meses. Para que possamos ter um controle dos movimentos que ocorrem nas vidas de vocês durante o decorrer do jogo, façam como o sr. Tobias e registrem em seu próprio diário todas as movimentações do jogo. 
Diário de

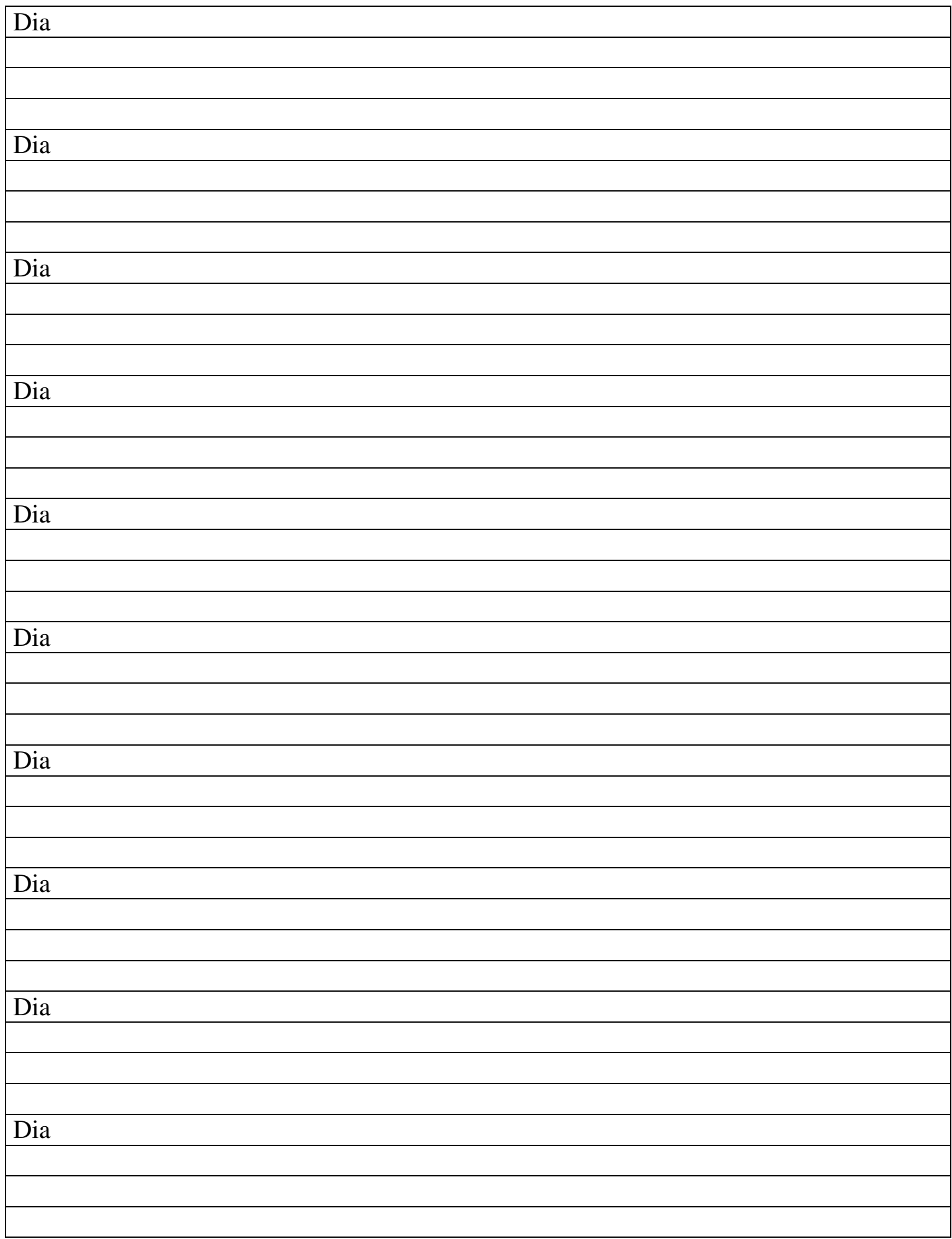


Somente após o término do jogo respondam a estas perguntas abaixo:

- Que problema esta forma de registrar o movimento diário de sua vida traz para o sr. Tobias?

- Se por acaso, as atividades diárias do sr. Tobias aumentarem consideravelmente. É possível que ele continue com esta forma de registro? Por quê?

- Afinal, qual é o problema que o sr. Tobias está enfrentando?

- Como ele pode resolver este problema? 


\section{Apêndice E \\ Códigos secretos: \\ Folha dos agentes}

Neste jogo você será um agente federal que está atrás de um grupo de terroristas, que planejam alguns atentados na cidade de São Paulo, você tem que detê-los antes que eles causem danos aos moradores da cidade. Para isto você precisa descobrir os códigos secretos que indicam o local dos atentados. Boa busca!!!

Tabela de cores e valores numéricos:

Primeira etapa

\begin{tabular}{|c|c|}
\hline Cor & $\begin{array}{c}\text { Valor } \\
\text { numérico }\end{array}$ \\
\hline Azul & 0 \\
\hline Amarelo & 1 \\
\hline Vermelho & 3 \\
\hline Verde & 5 \\
\hline
\end{tabular}

Segunda etapa:

\begin{tabular}{|c|c|}
\hline \multicolumn{2}{|c|}{ Agentes } \\
\hline Cor & $\begin{array}{c}\text { Valor } \\
\text { numérico }\end{array}$ \\
\hline Amarelo & 4 \\
\hline Vermelho & 6 \\
\hline Verde & 8 \\
\hline
\end{tabular}

Terceira etapa:

\begin{tabular}{|c|c|}
\hline \multicolumn{2}{|c|}{ Agentes } \\
\hline Cor & $\begin{array}{c}\text { Valor } \\
\text { numérico }\end{array}$ \\
\hline Amarelo & 2 \\
\hline Verde & 6 \\
\hline
\end{tabular}




\section{Códigos secretos - Folha dos terroristas}

Neste jogo você será um agente federal que está atrás de um grupo de terroristas, que planejam alguns atentados na cidade de São Paulo, você tem que detê-los antes que eles causem danos aos moradores da cidade. Para isto você precisa descobrir os códigos secretos que indicam o local dos atentados. Boa busca!!!

Tabela de cores e valores numéricos:

Primeira etapa

\begin{tabular}{|c|c|}
\hline Cor & $\begin{array}{c}\text { Valor } \\
\text { numérico }\end{array}$ \\
\hline Azul & 0 \\
\hline Amarelo & 1 \\
\hline Vermelho & 3 \\
\hline Verde & 5 \\
\hline
\end{tabular}

\begin{tabular}{|c|c|}
\hline \multicolumn{2}{|c|}{ Terroristas } \\
\hline Cor & $\begin{array}{c}\text { Valor } \\
\text { numérico }\end{array}$ \\
\hline Azul & 2 \\
\hline Amarelo & 4 \\
\hline Vermelho & 6 \\
\hline Verde & 8 \\
\hline
\end{tabular}

Segunda etapa:

\begin{tabular}{|c|c|}
\hline \multicolumn{2}{|c|}{ Terroristas } \\
\hline Cor & $\begin{array}{c}\text { Valor } \\
\text { numérico }\end{array}$ \\
\hline Vermelho & 3 \\
\hline Amarelo & 2 \\
\hline Verde & 6 \\
\hline
\end{tabular}

Terceira etapa: 
Folha de Registro dos terroristas

\begin{tabular}{|l|l|l|l|}
\hline Rodada & Seqüência de cores & Seqüência numérica & Dica \\
\hline 1 & & & \\
\hline 2 & & & \\
\hline 3 & & & \\
\hline 4 & & & \\
\hline 5 & & & \\
\hline & & & \\
\hline & & & \\
\hline & & & \\
\hline & & & \\
\hline & & & \\
\hline & & & \\
\hline & & & \\
\hline & & & \\
\hline & & & \\
\hline & & & \\
\hline
\end{tabular}




\section{Apêndice F \\ Descubra: \\ Tabela de registro}

\begin{tabular}{|c|c|l|l|}
\hline \multicolumn{5}{|l|}{ Nome: } \\
\hline Rodada & Seqüência de cores & Seqüência numérica & Resultado \\
\hline 1 & & & \\
\hline 2 & & & \\
\hline & & & \\
\hline & & & \\
\hline & & & \\
\hline & & & \\
\hline & & & \\
\hline & & & \\
\hline & & & \\
\hline
\end{tabular}

\section{Descubra - tabela do desafiante}

Primeira etapa

\begin{tabular}{|c|c|}
\hline Cor & Valor numérico \\
\hline Azul & 1 \\
\hline Amarelo & $?$ \\
\hline
\end{tabular}

\begin{tabular}{|c|c|}
\hline Cor & Valor numérico \\
\hline Amarelo & 1 \\
\hline Vermelho & $?$ \\
\hline Verde & 5 \\
\hline
\end{tabular}

Segunda etapa:

\begin{tabular}{|c|c|}
\hline Cor & Valor numérico \\
\hline Azul & 1 \\
\hline Vermelho & 2 \\
\hline Amarelo & 4 \\
\hline Verde & $?$ \\
\hline
\end{tabular}

Terceira etapa: 


\section{Descubra - tabela do desafiado}

\section{Primeira etapa}

\begin{tabular}{|c|c|}
\hline Cor & $\begin{array}{c}\text { Valor } \\
\text { numérico }\end{array}$ \\
\hline Azul & 1 \\
\hline Amarelo & 3 \\
\hline
\end{tabular}

Segunda etapa:

\begin{tabular}{|c|c|}
\hline Cor & $\begin{array}{c}\text { Valor } \\
\text { numérico }\end{array}$ \\
\hline Amarelo & 1 \\
\hline Vermelho & 3 \\
\hline Verde & 5 \\
\hline
\end{tabular}

Terceira etapa:

\begin{tabular}{|c|c|}
\hline Cor & $\begin{array}{c}\text { Valor } \\
\text { numérico }\end{array}$ \\
\hline Azul & 1 \\
\hline Vermelho & 2 \\
\hline Amarelo & 4 \\
\hline Verde & 6 \\
\hline
\end{tabular}




\section{Apêndice G Equações - Atividade}

Durante os dois últimos encontros, nós trabalhamos com seqüências de cores e com o jogo de dardos. Inicialmente, nas sequiências de cores tivemos somente a preocupação de descobri-las utilizando-se de pinos coloridos. Depois nós atribuímos as cores valores numéricos e passamos a trabalhar somente com números e com as operações matemáticas (adição e subtração), surgindo assim expressões numéricas e posteriormente surgiram as primeiras equações.

Dando continuidade as atividades, faça o que se pede abaixo.

ATIVIDADES:

Descubra o valor da cor que está faltando em cada situação posta para você.

\begin{tabular}{|l|l|}
\hline \multicolumn{1}{|c|}{ Cor } & Valor \\
\hline Azul & 2 \\
\hline Verde & $?$ \\
\hline Vermelho & 4 \\
\hline
\end{tabular}

\begin{tabular}{|l|l|l|}
\hline Seq. de cores & Equação & Resposta \\
\hline Azul e verde & Azul $+=5$ & \\
\hline verde e azul & $-\mathrm{Az}=1$ & \\
\hline Vermelho e verde & $\mathrm{V}+?=7$ & \\
\hline Vermelho e verde & $\mathrm{V}-?=1$ & \\
\hline
\end{tabular}

\begin{tabular}{|l|l|}
\hline \multicolumn{1}{|c|}{ Cor } & Valor \\
\hline Azul & 5 \\
\hline Verde & $?$ \\
\hline Vermelho & 6 \\
\hline
\end{tabular}

\begin{tabular}{|l|l|l|}
\hline Seq. de cores & Equação & Resposta \\
\hline Azul e verde & $5+$ verde $=12$ & \\
\hline Vermelho e verde & $?+6=13$ & \\
\hline verde e azul & $\mathrm{Vd}-5=2$ & \\
\hline Vermelho e verde & $\mathrm{Vd}-6=1$ & \\
\hline
\end{tabular}

\begin{tabular}{|l|l|}
\hline \multicolumn{1}{|c|}{ Cor } & Valor \\
\hline Azul & 3 \\
\hline Verde & $?$ \\
\hline Vermelho & 9 \\
\hline
\end{tabular}

\begin{tabular}{|l|l|l|}
\hline Seq. de cores & Equação & Resposta \\
\hline Azul, azul e verde & $3+3-\mathrm{vd}=1$ & \\
\hline Azul, verde e azul & $3+\mathrm{vd}-3=5$ & \\
\hline Vermelho, verde e azul & $9+\mathrm{vd}-3=11$ & \\
\hline Vermelho, verde e verde & $9+\mathrm{vd}+\mathrm{vd}=19$ & \\
\hline
\end{tabular}

\begin{tabular}{|l|l|}
\hline \multicolumn{1}{|c|}{ Cor } & Valor \\
\hline Azul & 2 \\
\hline Verde & $?$ \\
\hline Vermelho & 3 \\
\hline
\end{tabular}

\begin{tabular}{|l|l|l|}
\hline Seq. de cores & Equação & Resposta \\
\hline & $3+v d-2+v d=v d+9$ & \\
\hline & $2+v d+3=13$ & \\
\hline & $3=v d-3-2$ & \\
\hline & $9=v d+3-2$ & \\
\hline
\end{tabular}


Agora escreva você todas as equações possíveis para os resultados indicados e ache o valor desconhecido:

\begin{tabular}{|l|l|}
\hline \multicolumn{1}{|c|}{ Cor } & Valor \\
\hline Azul & 1 \\
\hline Verde & $?$ \\
\hline Vermelho & 6 \\
\hline
\end{tabular}

a) Resultado 10:

b) Resultado 2:

c) Resultado 8:

d) Resultado 16:

e) Resultado 1: 


\section{ATIVIDADE}

No jogo de dardos, um dos participantes esqueceu de registrar o valor de uma das partes do alvo, mas ele anotou todos a pontuação final de cada jogador. Descubra o valor da região do alvo em cada situação (ah!! Os pontos pretos são os dardos) e escreva a equação correspondente a cada situação:

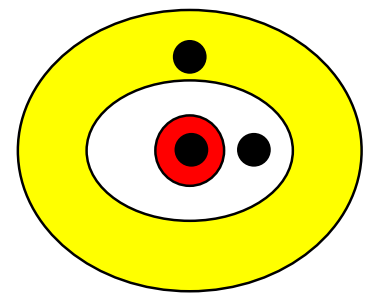

\begin{tabular}{|l|l|}
\hline Total de pontos & $\mathbf{1 7 5}$ \\
\hline Região & Valor \\
\hline Amarela & 25 \\
\hline Branca & $?$ \\
\hline Vermelha & 100 \\
\hline
\end{tabular}

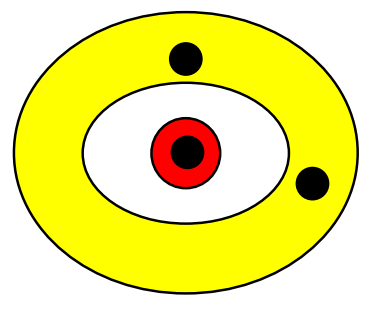

\begin{tabular}{|l|l|}
\hline Total de pontos & $\mathbf{5 0}$ \\
\hline Região & Valor \\
\hline Amarela & 10 \\
\hline Branca & 20 \\
\hline Vermelha & $?$ \\
\hline
\end{tabular}

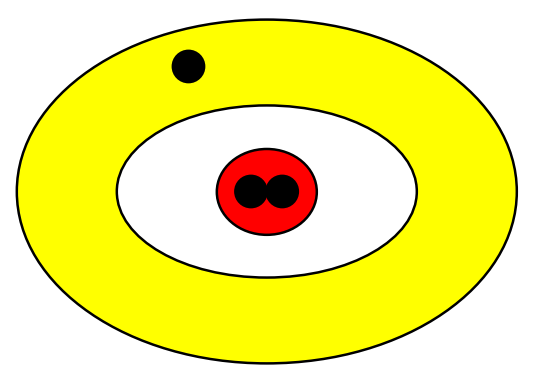

\begin{tabular}{|l|l|}
\hline Total de pontos & $\mathbf{1 3 0}$ \\
\hline Região & Valor \\
\hline Amarela & $?$ \\
\hline Branca & 30 \\
\hline Vermelha & 60 \\
\hline
\end{tabular}

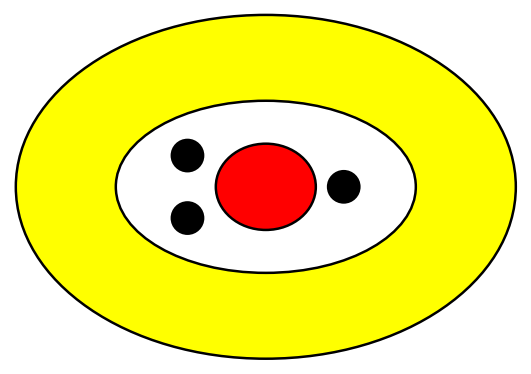

\begin{tabular}{|l|l|}
\hline Total de pontos & $\mathbf{6 0}$ \\
\hline Região & Valor \\
\hline Amarela & 10 \\
\hline Branca & $?$ \\
\hline Vermelha & 60 \\
\hline
\end{tabular}

